\title{
Competition between Hordeum vulgare L. and Chenopodium album L. with different dates of emergence of
} Chenopodium album

\author{
W. Th. Elberse and H. N. de Kruyf \\ Centre for Agrobiological Research (CABO), P.O. Box 14, 6700 AA Wageningen, \\ the Netherlands
}

Accepted: 1 June 1978

Key words: Hordeum vulgare, Chenopodium album, spring barley, competition, simulation

\section{Summary}

Under controlled conditions competition experiments were carried out with Hordeum vulgare L. (spring barley) and Chenopodium album L. (fat hen). This experiment was also simulated with a computer programme written in CSMP (Continuous System Modeling Program) on the basis of a model of Baeumer \& de Wit (1968). Goal of these experiments was:

a) determining the competitive ability of Chenopodium with respect to Hordeum and also to what extent earlier sowing of Chenopodium would affect this;

b) examining the extent to which the model of Baeumer \& de Wit applies to these species.

Evidence was found that when Chenopodium was sown 7 days earlier, it could not compete with Hordeum, but when this period was 21 and 31 days, Hordeum could no longer compete with Chenopodium. This result is hardly influenced by the applied densities of Chenopodium plants.

Correspondence between the simulated and observed yields was rather poor initially, but could be considerably improved by correcting the model with the length factor. For this, the observed difference in length growth between the two species was included in the model. This corresponds with the findings of Baeumer $\&$ de Wit (1968) with long and short peas.

Based on the simulation results it could be concluded that light interception is probably the most important competition factor between Chenopodium and Hordeum. Simulating a series of 7, 21, and 31 days earlier germination for Chenopodium demonstrated that the critical period in which Chenopodium can just maintain itself in a mixture with Hordeum, is about 15 days. Attention is called to the fact that the result of a competition experiment carried out under controlled 
conditions in a climate room cannot be used without comment for a predicting value under field conditions.

\section{Introduction}

Weeds compete with a crop for light, water and nutrients. Detriment to the crop, however, may vary considerably. The rate and the efficiency at which the plants occupy the available space determines the final yield of the crop. The term 'space' is a general expression for growth factors.

Supplementary to the competition theory developed by de Wit in 1960, de Wit \& van den Bergh (1965) introduced the term Relative Yield Total (RYT). With this concept the space occupied by different species can be compared to each other. With cultivated crops (except for legumes), in general, RYT $=1$ (Trenbath, 1974), so the species compete for the same space. In this case cultivation practices in order to obtain a closed green crop canopy as soon as possible (sowing density, row distance, date of seeding, pre-germinated seed, planting instead of sowing, etc.) will be an effective way of weed control.

Based on the competition theory of de Wit (1960), Baeumer \& de Wit (1968) developed a mathematical model with which the yields of species in a mixture can be predicted from their yields in monocultures of different plants densities. This model can be used in studying the competition phenomena between a crop and wild plant species. Evaluation of the model with experiments on oats, barley and long and short peas brought out some limitations. The simulated and actual yields of oats and barley were found to correspond well, but there was not much correspondence in the yields of the long and short peas. When the difference in plant length was introduced into the model, the simulated and actual yields showed better correspondence. The predicting merit of this model only functions under conditions in which the species occupy the same space (RYT $=1$ ). When the two species do not occupy the same space $(\mathrm{RYT} \neq 1)$, this model is not suitable.

Spacing and competition experiments were carried out under controlled conditions with Hordeum vulgare L. (spring barley) and Chenopodium album L. (fat hen). Goal of this study was:

a) determining the competitive ability of Chenopodium album with respect to Hordeum vulgare and also to what extent earlier germination of Chenopodium album would affect this;

b) examining to what extent the model of Baeumer $\&$ de Wit applies to these two species.

\section{Theoretical background}

When species compete for the same space (de Wit, 1960),

$$
O_{1}=\frac{k_{12} z_{1}}{k_{12} z_{1}+z_{2}} M_{1} \text { and } O_{2}=\frac{z_{2}}{k_{12} z_{1}+z_{2}} M_{2}
$$

$O_{1}$ and $O_{2}$ are the yields of the species 1 and 2 in the mixture and $M_{1}$ and $M_{2}$ their 
yields in monoculture, respectively; $z_{1}$ and $z_{2}$ are the relative plant densities in a replacement series $\left(z_{1}+z_{2}=1\right)$.

$k_{12}$ is defined as the relative crowding coefficient of species 1 with respect to species 2 . When $k_{12}=1$ both species show the same competitive ability, but when $k_{12}>1$ species 1 will suppress species 2 in a mixture.

The concept Relative Yield Total (RYT) was defined by de Wit \& van den Bergh (1965) as the sum of the relative yields $(r)$ of the species:

$$
\mathrm{RYT}=r_{1}+r_{2}=\frac{O_{1}}{M_{1}}+\frac{O_{2}}{M_{2}}
$$

The hyperbolic functions (1) only apply when the species compete for the same space, so when RYT $=1$ and when the relative crowding coefficient $k_{12}$ is independent of the relative planting densities. The relative replacement rate $p$ is defined by:

$\frac{\mathrm{n}_{r_{\mathrm{a}}} / \mathrm{m}_{r_{\mathrm{a}}}}{\mathrm{n}_{r_{\mathrm{b}}} / \mathrm{m}_{r_{\mathrm{b}}}}$ (de Wit \& van den Bergh, 1965),

in which $n$ and $m$ symbolize the different times at which the relative yields are determined.

The intraspecific competition is studied on the basis of spacing experiments. Spacing experiments are identical to replacement series in which one of the two species is absent.

The yield of a species in monoculture as a function of the plant density generally results in a saturation curve. Such a relation can be described as follows:

$$
O=\frac{\beta Z}{\beta Z+1} \Omega
$$

and on day $\mathrm{t}$ :

$$
O_{\mathrm{t}}=\frac{\beta_{\mathrm{t}} Z}{\beta_{\mathrm{t}} Z+1} \Omega_{\mathrm{t}}
$$

$Z$ is the seed or plant density (e.g. plants per $\mathrm{m}^{2}$ ) and $O$ is the yield, e.g. in $\mathrm{g} / \mathrm{m}^{2}$. $\Omega$ is the maximum yield (saturation level) at very high plant densities:

$$
\operatorname{Lim}_{Z \rightarrow \infty}(O)=\operatorname{Lim}_{Z \rightarrow \infty} \frac{\beta Z}{\beta Z+1} \Omega=\Omega
$$

$\beta \Omega$ is the potential yield of a single plant without competition of other plants:

$$
\operatorname{Lim}_{Z \rightarrow 0} \frac{O}{Z}=\operatorname{Lim}_{Z \rightarrow 0} \frac{\beta}{\beta Z+1} \Omega=\beta \Omega
$$

The value of $\beta$ shows the extent of the saturation and may be considered the 'space' occupied by a single plant at a certain moment. 
With the yield data of a spacing experiment with at least two different plant densities and more harvests per growing period the time curves of $\beta$ and $\Omega$ can be calculated. According to Baeumer \& de Wit (1968) and de Wit (1970) with these data the yields of two species in a mixture can be predicted.

The concept Relative Space (RS) is important in such a calculation. The relative space occupied by one of the species at a certain moment is defined by the quotient $O_{\mathrm{t}} / \Omega_{\mathrm{t}}$.

$$
\begin{aligned}
& \text { relative space }=\frac{O_{\mathrm{t}}}{\Omega_{\mathrm{t}}}=\frac{\beta_{\mathrm{t}} Z}{\beta_{\mathrm{t}} Z+1}=o_{\mathrm{t}} \\
& \text { on day }(\mathrm{t}+1): o_{\mathrm{t}+1}=\frac{\beta_{\mathrm{t}+1} Z}{\beta_{\mathrm{t}+1} Z+1}
\end{aligned}
$$

After some calculations it is found that:

$$
o_{\mathrm{t}+1}=\frac{\beta_{\mathrm{t}+1}}{\left(\beta_{\mathrm{t}+1}-\beta_{\mathrm{t}}\right) o_{\mathrm{t}}+\beta_{\mathrm{t}}} o_{\mathrm{t}}
$$

The relative space occupied by species 1 in a mixture with species 2 on day $t+1$ then is:

$$
o_{\mathbf{1}_{\mathrm{t}+1}}=\frac{\beta_{\mathbf{1}_{\mathrm{t}+1}}}{\left(\beta_{\mathbf{1}_{\mathrm{t}+1}}-\beta_{\mathbf{1}_{\mathrm{t}}}\right)\left(o_{\mathbf{1}_{\mathrm{t}}}+o_{\mathbf{t}_{\mathrm{t}}}\right)+\beta_{\mathbf{1}_{\mathrm{t}}}} o_{\mathbf{1}_{\mathrm{t}}}
$$

And for species 2:

$$
o_{2_{\mathrm{t}+1}}=\frac{\beta_{2_{\mathrm{t}+1}}}{\left(\beta_{2_{\mathrm{t}+1}}-\beta_{2_{\mathrm{t}}}\right)\left(o_{1_{\mathrm{t}}}+o_{2_{\mathrm{t}}}\right)+\beta_{2_{\mathrm{t}}}} o_{2_{\mathrm{t}}}
$$

Eq. 6, 7, 8 and 9 enable a stepwise calculation (simulation) of the relative space occupied by both species in the mixture in the course of time. A similar simulation was done for Hordeum and Chenopodium with the aid of a computer programme written in CSMP (Continuous System Modeling Program), analogous to the mentioned calculation method. The concept relative space in this programme functions as a 'state variable' (de Wit \& Goudriaan, 1978). The rate at which this 'state variable' changes is found by differentiating it with time:

$$
\frac{\mathrm{d}(\mathrm{RS})}{\mathrm{dt}}=\frac{\mathrm{d} \beta / \mathrm{dt}}{\beta} \times \mathrm{RS} \times(1-\mathrm{RS})
$$

The relative growth rate $\frac{\mathrm{d} \beta / \mathrm{dt}}{\beta}$ is not constant, but dependent on time. Moreover, in this equation the maximum of the 'state variable' is RS 1 . When analogous to the Eq. 8 and 9 the relative spaces of both species may be added, so when the plants do not distinguish between the space occupied by the one species or by the other, the situation in the mixture is decribed by the following equations: 


$$
\begin{aligned}
& \frac{\mathrm{d}\left(\mathrm{RS}_{1}\right)}{\mathrm{dt}}=\frac{\mathrm{d} \beta_{1} / \mathrm{dt}}{\beta_{1}} \times \mathrm{RS}_{1} \times(1-\mathrm{SRS}) \\
& \frac{\mathrm{d}\left(\mathrm{RS}_{2}\right)}{\mathrm{dt}}=\frac{\mathrm{d} \beta_{2} / \mathrm{dt}}{\beta_{2}} \times \mathrm{RS}_{2} \times(1-\mathrm{SRS}) \\
& \mathrm{SRS}=\mathrm{RS}_{1}+\mathrm{RS}_{2} \\
& \mathrm{SRS}=\text { summarized relative space. }
\end{aligned}
$$

The factor $(1-$ SRS $)$ which varies from almost zero at the beginning of the growing period up to almost 1 at the end, characterizes the growth reduction due to the space already occupied by both species. The differentiation equations 11 and 12 are the basis of the simulation programme used (see de Wit/\& Goudriaan, 1978). Poor correspondence between the simulated and the actual yields indicates that the relative spaces occupied by the species in the mixture may not be added. In this case it can be roughly determined with the aid of this model which factor is determining the difference in space occupied by both species. In the case of the long and short peas the difference in length growth was found to be an important factor. The first correction of the model was achieved by bringing into account this difference in length growth, according to:

$$
\begin{aligned}
& \mathrm{SRS}_{1}=\mathrm{RS}_{1}+\left(\mathrm{H}_{2} / \mathrm{H}_{1}\right) \mathrm{RS}_{2} \\
& \mathrm{SRS}_{2}=\left(\mathrm{H}_{1} / \mathrm{H}_{2}\right) \mathrm{RS}_{1}+\mathrm{RS}_{2}
\end{aligned}
$$

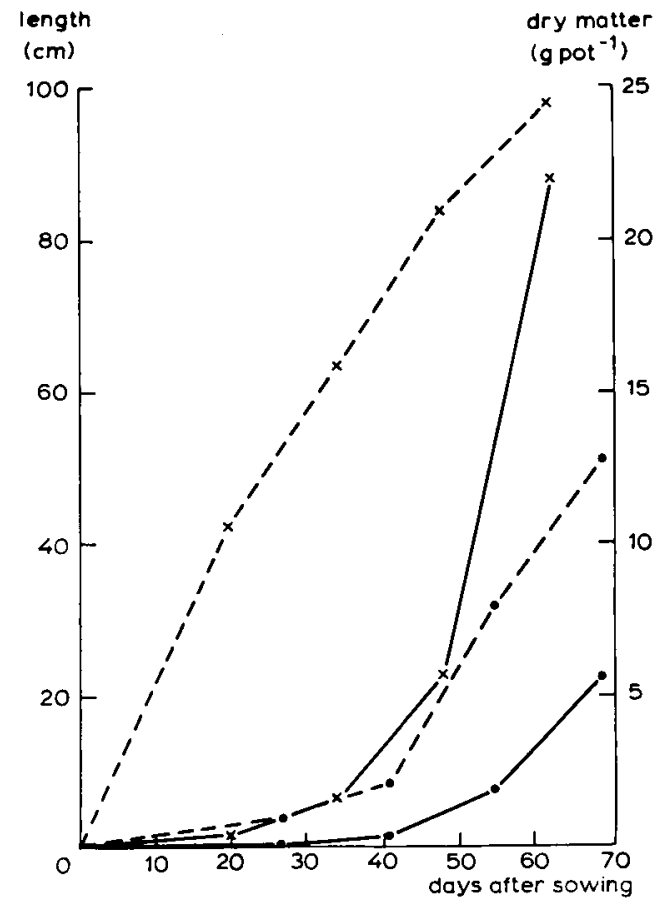

Fig. 1. Dry-mater production $(\longrightarrow$ ) and length growth (-- ) in time for Hordeum $(X)$ and Chenopodium (•). 
in which $\mathrm{H}_{1}$ and $\mathrm{H}_{2}$ represent the length of species 1 and species 2 , respectively. The trend in factor $\mathrm{H}_{1} / \mathrm{H}_{2}$ in time has been given as a function table in the programme (see de Wit \& Goudriaan, 1978).

Between the monocotyledonous Hordeum and the dicotyledonous Chenopodium there is difference in habit as well as in growth rhythm (Fig. 1). A study was made to see whether a correction of the model with the length factor would be sufficient in this case to attain a better correspondence between the simulated and the observed yields.

\section{Material and methods}

The spacing and replacement series experiments were carried out in a phytotron under controlled conditions.

Day length was 14 hours $\left(40 \mathrm{~W} \mathrm{~m}^{-2}, \mathrm{HRL}-\mathrm{R}\right)$ and the temperature during germination was $20^{\circ} \mathrm{C}$, after which it was gradually decreased to 17 or $18{ }^{\circ} \mathrm{C}$. Relative humidity varied from about $60 \%$ in the light period to about $75 \%$ during the dark period. Mitscherlich pots were used with a diameter of $20 \mathrm{~cm}$ (surface $\left.314 \mathrm{~cm}^{2}\right)$. Each pot was filled with $7 \mathrm{~kg}$ of poor sandy soil $(\mathrm{pH}-\mathrm{KCl} 5.6$; organic matter $3.7 \%$; coarse sand $73 \%$; total sand $90 \%$; clay fraction $6 \%$; $7 \mathrm{mg} / \mathrm{kg}$; $\mathrm{CaCO}_{3} 0.1 \% ; \mathrm{P} 470 \mathrm{mg} / \mathrm{kg} ; \mathrm{MgO} 68 \mathrm{mg} / \mathrm{kg}$ ) and fertilized with $7 \mathrm{~g}$ of ASF $(12 \% \mathrm{~N}, 10 \% \mathrm{P}, 18 \% \mathrm{~K})$. This basic fertilizer application corresponds with 60 meq N, 23 meq $P$, and 32 meq $\mathrm{K}$ and was considered sufficient to avoid competition for minerals. Water was supplied by weighing the pots every other day and adding water up to $20 \%$ moisture content of the soil. To avoid as much as possible environmental differences within the room the pots were placed on a trolley which was moved every other day and moreover the pots on one trolley were regularly changed. Interaction of plants in different pots was avoided by placing baskets over the pots, which also provided the support which the plants normally get in a crop. Provisional germination experiments showed a germination percentage of 80 to $90 \%$ for Hordeum, but one of $20 \%$ only for Chenopodium. The seed coat of Chenopodium was scarified by abrasion with sand paper, which increased this percentage to ca. $45 \%$. To prevent drop-outs two seeds of Hordeum were sown in the places for one plant and, if necessary, thinned after emergence. To obtain the desired number of Chenopodium plants a liberal amount of seed was evenly sown; after emergence the plants were thinned to the desired number and correct distribution on the pot surface.

\section{Spacing experiment}

For Hordeum a series was set up with plant densities of 1, 2, 4 and 16 plants per pot. Each plant density had four replicates per harvest and the harvests took place $20,34,48$ and 62 days after sowing.

The plants were cut above the soil surface, the number of tillers was counted and their lengths measured. The dry-matter production was determined by weighing the plant material after 24 hours of drying at $80^{\circ} \mathrm{C}$. 


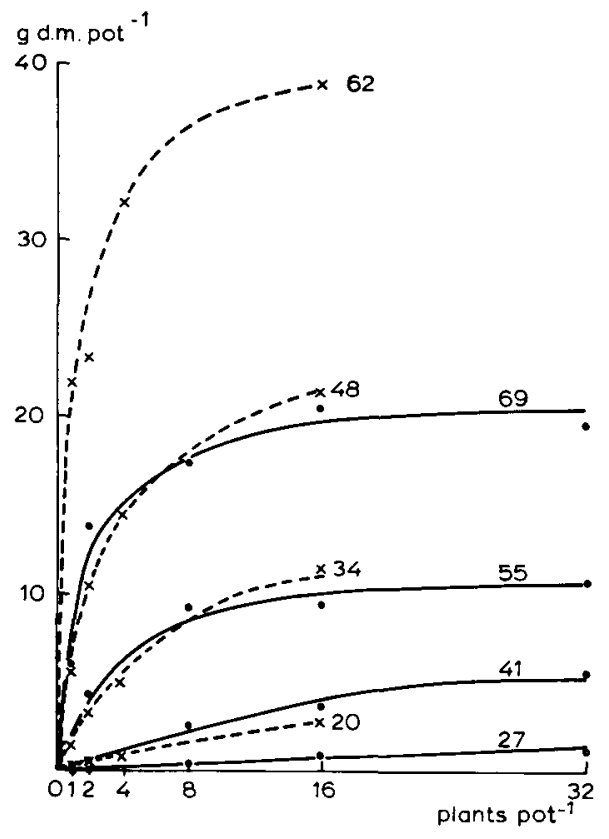

Fig. 2. Relationship between dry matter production and density at four harvest times. $\times---x$ Hordeum, $\longrightarrow$ Chenopodium.

For Chenopodium a series was set up with plant densities of $1,2,8,16$ and 32 plants per pot, with four replicates per plant density per harvest. Harvests were carried out $27,41,55$ and 69 days after sowing.

The results of the spacing experiments with Hordeum and Chenopodium are presented in Fig. 2. In the first harvest the yield per pot increases linearly with plant density for both species. After this harvest, however, intra-specific competition starts. In Chenopodium intra-specific competition already begins at a much lower yield level than with Hordeum, which is quite understandable in the light of the completely different growth habits of the two plant species. The monocotyledon Hordeum grows mainly vertically and only at a later stage begins to spread by tillering; growth of a dicotyledon, like Chenopodium, from the beginning onwards is directed also horizontally. Due to the horizontal leaf orientation and lateral branching, the overground parts of this species will sooner start interfering with each other. After 62 days the saturation level of the yield per pot of Hordeum is ca. $40 \mathrm{~g}$, a factor two higher than that of Chenopodium. This production corresponds with a growth rate of $20.5 \mathrm{~g} \mathrm{~m}^{-2}$ day-1, which equals the potential growth rate of most of the Dutch agricultural crops (de Wit, 1970).

In addition to a difference in habit the two plant species also differ in growth rhythm, which is brought out clearly in the growth curves of both species (Fig. 1). The large Hordeum seeds enable rapid initial growth in the first period after germination, when the photosynthetic apparatus still has to be developed and the energy required for growth mainly comes from the seed. The growth curves of Hordeum show that this energy is mainly invested in length growth in the initial 


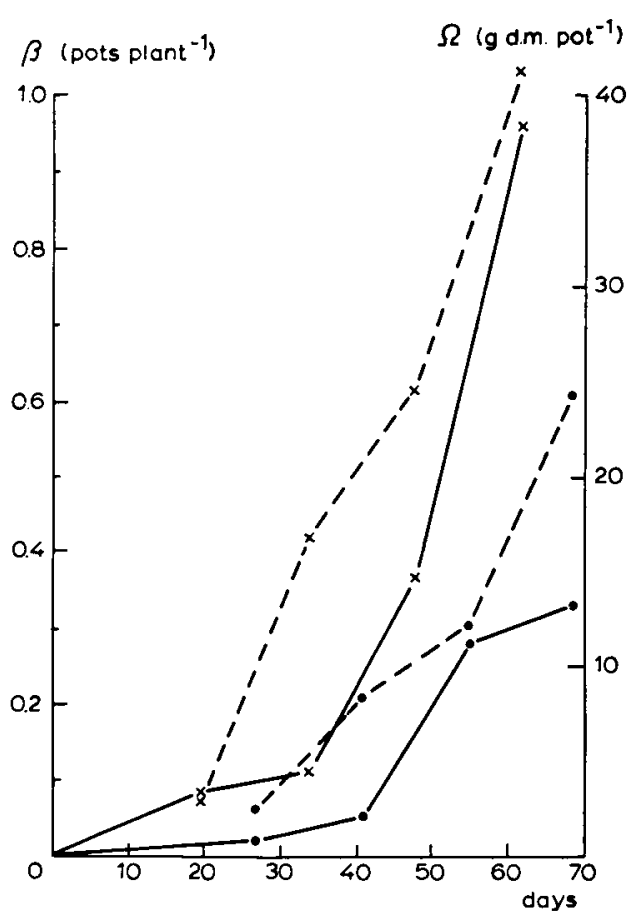

Fig. 3. Time curves of $\beta(\longrightarrow)$ and $\Omega$ $(---)$ for Hordeum $(X)$ and Chenopo$\operatorname{dium}(\bullet)$.

phase and only at a much later stage, when the plant begins to tiller, dry-matter production is started and then shows an exponential character. Such characteristics enable a rapid closing of the green canopy.

Initial growth of Chenopodium is low and only after emergence of the second or third leaf pair growth will be of an exponential character. Contradictory to Hordeum the dry-matter production in Chenopodium runs more or less parallel to length growth. Despite the great difference in length growth, the complementary leaf orientation of the two species probably prevents Hordeum from intercepting all the light for Chenopodium in a mixture.

For both species $\beta$ and $\Omega$ values have been calculated according to the graphic method, in which the inverse of the overground dry-matter production is plotted against the inverse of plant density. The points lie on a straight line. $\beta$ is equal to the distance of the origin to the intersection of the curve with the abscis. The value of $\Omega$ is equal to the inverse of the distance of the origin to the intersection of the line with the ordinate. The resulting time curves of $\beta$ and $\Omega$ for both species are presented in Fig. 3.

\section{Competition experiments}

First competition experiment

Together with the spacing experiment a competition experiment was set up. This trial consisted of three replacement series: 


$\begin{array}{lrrr}\text { a. Hordeum } & 16 & 8 & 0 \\ \text { Chenopodium } & 0 & 4 & 8 \\ \text { a. Hordeum } & 16 & 8 & 0 \\ \text { Chenopodium } & 0 & 8 & 16 \\ \text { c. Hordeum } & 16 & 8 & 0 \\ \text { Chenopodium } & 0 & 16 & 32\end{array}$

In these three series the plant density of Chenopodium was doubled each time, while that of Hordeum remained constant. Each combination had four replicates per harvest and harvesting took place 41, 55 and 69 days after sowing Chenopodium. In order to approach field conditions to some extent, under which the seed of Chenopodium is already present in the soil when Hordeum still has to be sown, Chenopodium was sown one week earlier. Further treatment of the experiment was identical to that of the spacing experiment.

Second competition experiment

In order to study the conditions under which Chenopodium can suppress Hordeum in the mixture, a second competition experiment was set up which also consisted of three replacement series:

\begin{tabular}{|c|c|c|c|c|}
\hline Hordeum & 16 & 12 & 6 & 0 \\
\hline Chenopodium & 0 & 4 & 10 & 16 \\
\hline Hordeum & 16 & 12 & 6 & 0 \\
\hline Chenopodium & 0 & 8 & 20 & 32 \\
\hline Hordeum & 32 & 24 & 12 & 0 \\
\hline Chenopodium & 0 & 8 & 20 & 32 \\
\hline
\end{tabular}

The series $d$ and $e$ are identical to the series $b$ and $c$ of the first competition experiment, on the understanding that the series $d$ and e include two mixtures instead of one; this has been done to enable a more accurate determination of the hyperbolic curve. The replacement series $\mathrm{f}$ is supposed to give an idea of the mutual competition of Chenopodium and Hordeum at very high plant densities of both species.

In this experiment two different series with respect to earlier sowing of Chenopodium were included: in one half Chenopodium was sown 21 days earlier than Hordeum and in the other half 31 days earlier. Each combination was replicated three times per harvest and both series (21 and 31 days earlier) were harvested three times. Further treatment of this trial was the same as that in the first competition experiment.

\section{Results}

The results of the replacement series $a, b$, and $c$ are reported in the replacement diagrams of Fig. 4. Of each series, for the three harvest dates (in the diagrams indicated by roman figures I, II, and III) replacement diagrams are given, including $k$ values and RYT's. 
The $k$ values characterizing the hyperbolic functions demonstrate that during the growing period Chenopodium is replaced by Hordeum. The RYT values at the first harvest are clearly smaller than one. For the second and third harvests they differ, in view of the spread of the separate observations, not reliably from one. A conclusion to be drawn from the first competition experiment is that, despite Chenopodium being sown one week in advance of Hordeum and doubling of the number of Chenopodium plants, Chenopodium is clearly at a disadvantage of Hordeum and will ultimately disappear.

The course lines of all replacement series (Fig. 5) show that when Chenopodium is sown one week earlier than Hordeum, Chenopodium is suppressed by Hordeum ( $p_{\text {H.c. }}$ increases steadily). With sowings of Chenopodium of three weeks in advance of Hordeum, at first Chenopodium replaced Hordeum $\left(\rho_{\text {H.C. }}<1\right.$ ), but afterwards $P_{\text {H.c. }}$ stayed about constant (horizontal course lines). Finally, with an earlier start of Chenopodium of 31 days, Hordeum is replaced by Chenopodium at a constant
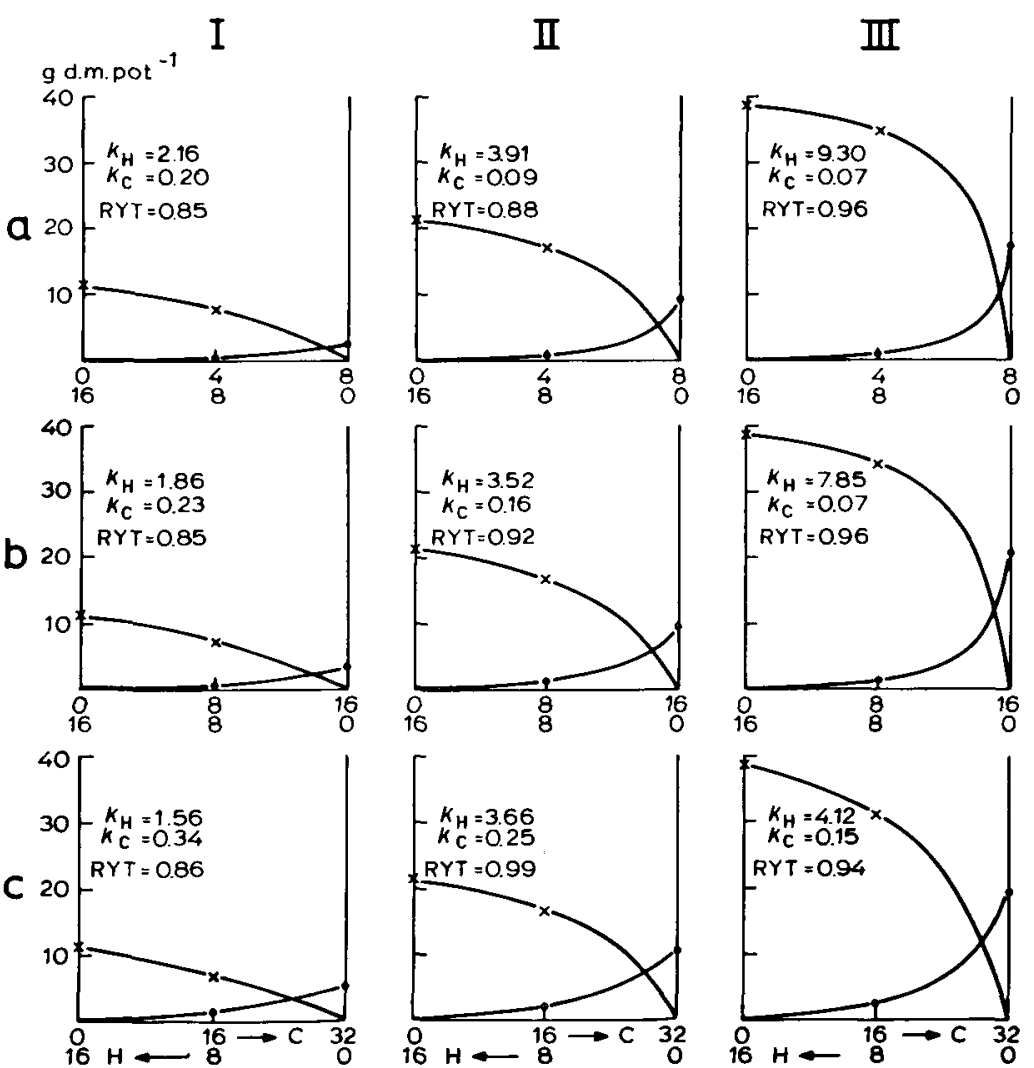

Fig. 4. Replacement diagrams presenting dry matter yield of Hordeum $(X)$ and Chenopodium (•) for the replacement series a, b and c at the harvest times I, II and III (41, 55 and 69 days respectively after sowing Chenopodium). Hordeum was sown 7 days after Chenopodium. 


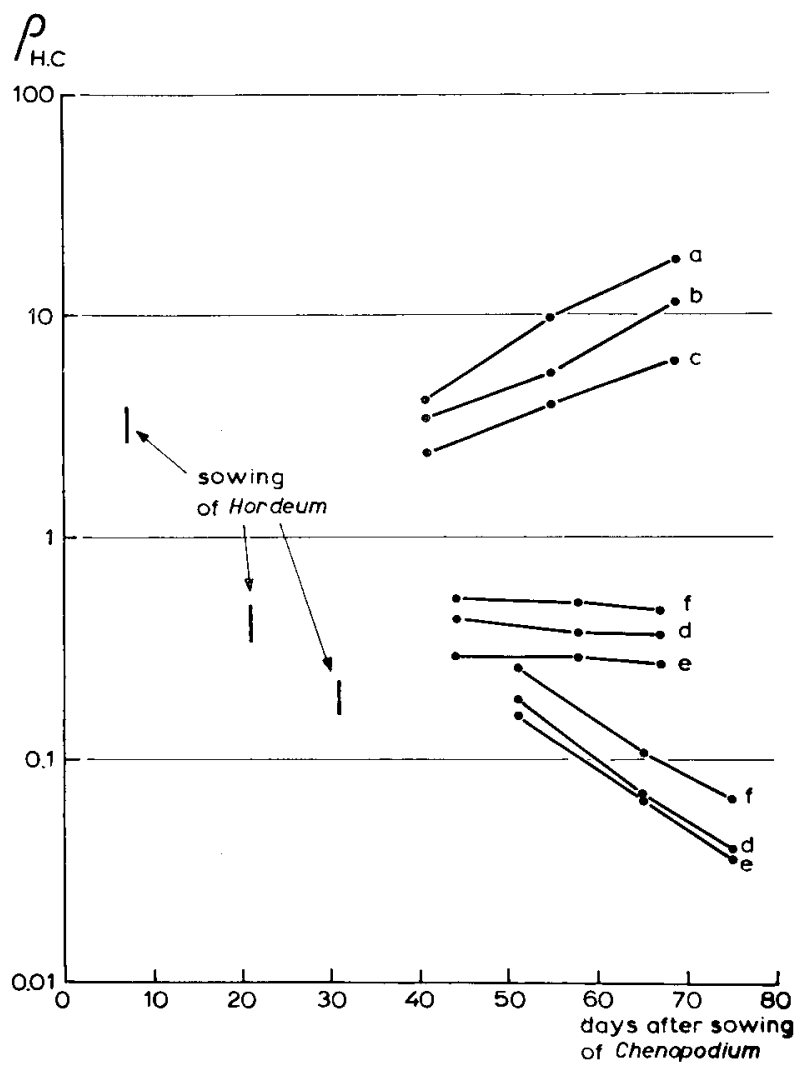

Fig. 5. Relative replacement rates in time of Hordeum with respect to Chenopodium. In replacement series a, b and c Hordeum was sown 7 days after Chenopodium. In the upper and lower $\mathrm{f}, \mathrm{d}$ and e replacement series Hordeum was sown 21 and 31 days respectively after Chenopodium.

rate during the entire experimental period. Increase of the number of Chenopodium plants gives a small advantage for Chenopodium at first, but afterwards the course lines are parallel, indicating that the number of Chenopodium plants does not influence the result of competition.

\section{Simulation}

Growth of Chenopodium and Hordeum in a mixture was simulated according to the theoretical model described in the section 'Theoretical background'. The results obtained on the basis of the programme of de Wit \& Goudriaan (1978) are presented in Fig. 6A. It appears that the correspondence between the observed and simulated growth of Chenopodium and Hordeum is very poor. The model developed for two monocotyledons (oats and barley, see also the results of Rerkazem (1978) with mixtures of wheat and annual ryegrass), evidently cannot be 

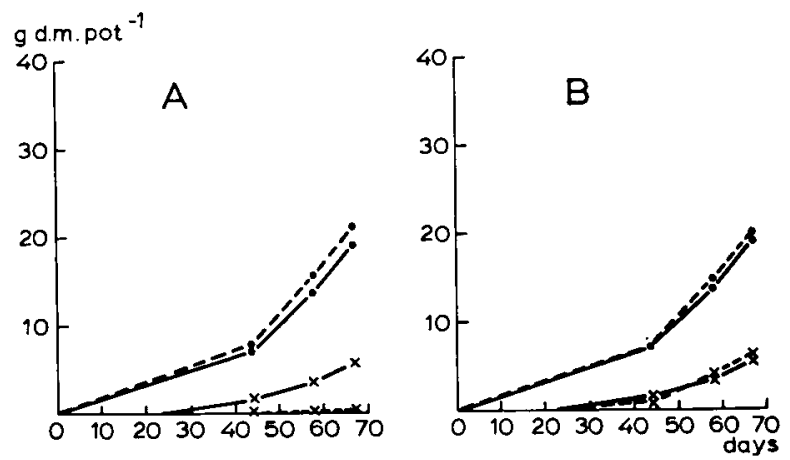

Fig. 6. Observed (- $\longrightarrow$ and calculated (- --$)$ yield in time of Hordeum $(X)$ and Chenopodium (•) of an 8-8 mixture. Hordeum was sown 21 days after Chenopodium. A. Simulated without taking into account length growth. B. Simulated with taking into account length growth.

applied without adjustment to describe the growth of a monocotyledon and a dicotyledon, which moreover vary in growth habit and growth rhythm (see Fig. 1). This result was to be expected, in view of the findings of Baeumer \& de Wit with this model in a mixture of long and short peas. Like them, we tried to improve the model by bringing into the model the differences in length growth between the species (see 'Theoretical background'). The result is presented in Fig. 6B. The correspondence between the observation and simulation is now very acceptable. With this adapted programme growth of both species in a mixture was simulated with Chenopodium being sown 7, 21 and 31 days earlier, respectively.

The result is given in Fig. 7. The $p$ values of Hordeum with respect to Chenopodium have been calculated at various advantages of Chenopodium. This has been done on the basis of the experimental data as well as of the simulated data.

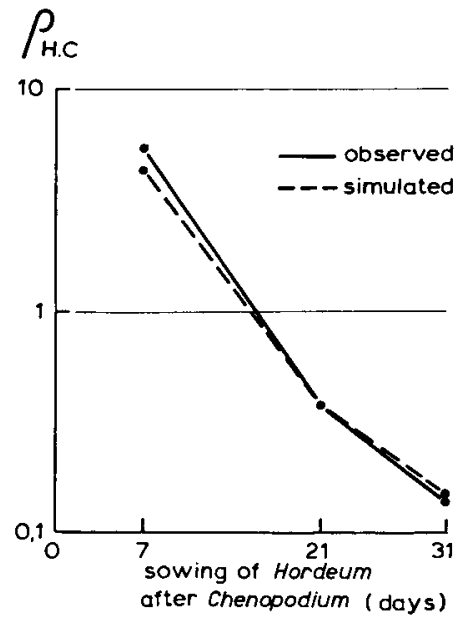

Fig. 7. Relationship between the relative replacement rate of Hordeum with respect to Chenopodium (calculated from the observed yields (- - ) and the simulated yields (-- 55 days after sowing Chenopodium) and the time Hordeum was sown after Chenopodium. 
When $\rho>1$, Chenopodium will disappear from the mixture and when $\rho<1$, Hordeum will disappear from the mixture. The graph shows that in the experiment as well as in the simulation the 'critical advantage' for Chenopodium is about 15 days.

\section{Discussion}

It has already been mentioned that the growth curves of Chenopodium and Hordeum (Fig. 1) show that the two species have a rather different growth rhythm. This is also brought out by the time curves for $\beta$ (Fig. 3).

In Hordeum $\beta$ increases exponentially contrary to Chenopodium for which the $\beta$ curve shows a much slower rise, while increase diminishes again at a lower level. Attention is called to the fact, however, that Chenopodium was flowering by the end of the experiment, whereas this was not so with Hordeum. Since the dry-matter in a plant is redistributed (seed production instead of growth of the photosynthetic area) during the reproductive phase, this certainly will have influenced the results.

Under the conditions prevailing in these experiments, when the two species start from an equal beginning, Hordeum has already occupied the available space before Chenopodium can do so. Chenopodium can neutralize this difference only, when it is sown earlier.

The simulation shows that the concept 'space', as used in the present paper, can be replaced by the term available light.

The model of Baeumer \& de Wit only applies when length growth of the two species does not differ to such an extent that one species is shading strongly the other. The initially poor correspondence between the simulated and observed yields suggested that this was indeed the case with Hordeum. Since the simulation could be appreciably improved by correction with the length factor (see Fig. 6B), this was very likely so. The correspondence between simulation and experiments probably could have been further improved by characterizing this shading effect of one species on the other better than with the length factor only, for example by using data like leaf area and leaf orientation and by stratified clipping.

The results of these experiments suggest that Chenopodium need not be a harmful weed in a Hordeum crop, provided sowing takes place betimes after preparing the seedbed. The experiments and the simulation based on the data of the spacing experiments showed that this period may not be longer than about 15 days. However, these results should be interpreted with due reserve; the experiments were carried out in a climate room under controlled conditions and adjusted to optimal growing conditions for Hordeum. In the field conditions for Hordeum will be much less favourable. It may be assumed that the widely fluctuating conditions in spring (time of sowing Hordeum) will favour rather a species like Chenopodium than a crop like Hordeum, in addition the aspect of germination may not be excluded under these conditions. It is evident that a predicting value for field conditions may not be attached without comment to a competition experiment in a climate room. 


\section{Acknowledgment}

The authors are very grateful to Ir W. de Groot for his support in these experiments.

\section{References}

Baeumer, K. \& C. T. de Wit, 1968. Competitive interference of plant species in monoculture and mixed stands. Neth, J. agric. Sci., 16: 103-122.

Rerkazem, K., 1978. Associated growth of wheat and annual ryegrass in mixtures and the effects on yield and yield components of wheat. Thesis, University of Western Australia, $392 \mathrm{pp}$.

Trenbath, B. R., 1974. Biomass productivity of mixtures. Adv. Agron. 26: 177-210.

Wit, C. T. de, 1960. On competition. Versl. landbouwk. Onderz. 66. 8; 82 pp.

Wit, C. T. de, 1970. On the modelling of competitive phenomena. Proc. Adv. Study Inst. Dynamics Numbers Popul. (Oosterbeek, Netherlands), 269-281.

Wit, C. T. de \& J. P. van den Bergh, 1965. Competition between herbage plants. Neth. J. agric. Sci. 13: 212-221.

Wit, C. T. de \& J. Goudriaan, 1978. Simulation of ecological processes, 2nd ed. Pudoc, Wageningen. (1st edition in 1974.) 